\section{Cureus}

Received 01/11/2019

Review began 01/17/2019

Review ended 01/20/2019

Published 02/01/2019

\section{(c) Copyright 2019}

Moyer et al. This is an open access article distributed under the terms of the Creative Commons Attribution License CC-BY 3.0., which permits unrestricted use, distribution, and reproduction in any medium, provided the original author and source are credited.

\title{
Kikuchi-Fujimoto Disease: An Atypical Presentation of a Rare Disease
}

\author{
Amanda Moyer ${ }^{1}$, Muhammad Z. Hanafi ${ }^{2}$, Teresa Scordino ${ }^{3}$, Michael Bronze ${ }^{4}$ \\ 1. Pediatrics, University of Oklahoma Health Sciences Center, Oklahoma City, USA 2. Gastroenterology, \\ University of Oklahoma Health Science Center, Oklahoma City, USA 3. Pathology, University of \\ Oklahoma Health Sciences Center, Oklahoma City , USA 4. Internal Medicine, University of Oklahoma \\ Health Sciences Center, Oklahoma City, USA
}

Corresponding author: Amanda Moyer, amanda_07@hotmail.com

\section{Abstract}

Kikuchi-Fujimoto disease (KFD), or necrotizing histiocytic lymphadenitis, is a rare cause of lymphadenopathy and fever. Although the clinical course is usually benign, KFD is often mistaken for malignancy or infection. Recognition of typical and atypical cases of KFD is necessary to avoid unnecessary interventions. Here we report an atypical presentation of KFD with diffuse lymphadenopathy and leukocytosis associated with high levels of circulating Epstein-Barr viral DNA.

Categories: Internal Medicine, Pathology, Rheumatology

Keywords: kikuchi fujimoto, lymphadenopathy, histiocytosis, lymphadenitis, epstein-barr

\section{Introduction}

Kikuchi-Fujimoto disease (KFD) is a benign lymphohistiocytic disorder characterized by lymphadenopathy (typically cervical), fatigue, and fever [1-2]. Additional common findings include hepatosplenomegaly, weight loss, elevated acute phase reactants, and leukopenia/lymphopenia [3].

The etiology of KFD is controversial. Some authors speculate that viral and autoimmune processes influence the development of KFD [4-5]. It generally resolves in one to four months, but has been associated with subsequent development of systemic lupus erythematous (SLE) [3, 5-6]. Excisional lymph node biopsy with hallmark findings confirms the diagnosis [7-8].

\section{Case Presentation}

A 20-year-old Caucasian female was admitted with one month of cervical lymphadenopathy and two months of fever, fatigue, night sweats, and 15-pound weight loss. A course of antibiotics two weeks prior did not improve her symptoms. A week prior to admission, she developed an intermittent diffuse urticarial rash.

Medical history was significant for poorly controlled type II diabetes and chronic pain. She was allergic to sulfa drugs and latex. Family history was unknown. She denied travel, drug and alcohol use, and sexual activity.

On presentation, the patient was febrile to $38.6^{\circ} \mathrm{C}$, with a heart rate of 135 beats per minute, respiratory rate of 18 breaths per minute, and blood pressure of 115/85 $\mathrm{mmHg}$. Examination was remarkable for diffuse, rubbery lymphadenopathy $(0.5 \mathrm{~cm} \times 1 \mathrm{~cm}-3 \mathrm{~cm} \times 3 \mathrm{~cm})$. A faint 


\section{Cureus}

erythematous, reticular rash was present on her legs.

Laboratory data demonstrated marked leukocytosis with eosinophilia. Inflammatory markers, uric acid, and lactate dehydrogenase were elevated (Table 1).

\begin{tabular}{|c|c|c|c|c|c|}
\hline Variable & Reference range & Day 0 & Day 3 & Day 6 & (Outpa \\
\hline \multicolumn{6}{|l|}{ Hematology } \\
\hline Hematocrit (\%) & $34.0-46.0$ & 37.5 & 35.4 & 31.6 & 29.1 \\
\hline $\begin{array}{l}\text { Hemoglobin } \\
(\mathrm{g} / \mathrm{dL})\end{array}$ & $12.0-16.0$ & 12.7 & 11.8 & 10.5 & 10 \\
\hline $\begin{array}{l}\text { White blood cell } \\
\text { count }\left(\mathrm{K} / \mathrm{mm}^{3}\right)\end{array}$ & $4.000-11.00$ & 47.70 & 24.38 & 12.02 & 10.66 \\
\hline \multicolumn{6}{|l|}{ Differential (\%) } \\
\hline Neutrophils & $39-78$ & 23 & 39 & 38 & \\
\hline Band forms & $0.0-12$ & 16 & 2.0 & 9.0 & - \\
\hline Lymphocyte & $15.0-46.0$ & 34 (6\% reactive) & 22.3 & 24.0 & 38.1 \\
\hline Monocytes & $2.0-14$ & 4.0 & 1.0 & 1.0 & 4.6 \\
\hline Eosinophils & $0.0-6.0$ & 21 & 26 & 23 & 7.0 \\
\hline Basophils & $0-2$ & 1 & 2 & 2 & - \\
\hline $\begin{array}{l}\text { Platelets } \\
\left(\mathrm{K} / \mathrm{mm}^{3}\right)\end{array}$ & $140-440$ & 126 & 114 & 183 & 388 \\
\hline $\begin{array}{l}\text { Mean } \\
\text { corpuscular } \\
\text { volume (fL) }\end{array}$ & 80.0-99.0 & 80.6 & 81.9 & 84 & 85.3 \\
\hline $\begin{array}{l}\text { Red cell } \\
\text { distribution width } \\
(\%)\end{array}$ & 11.0-15.0 & 15.2 & 15.6 & 15.8 & 19.4 \\
\hline $\begin{array}{l}\text { Westergren } \\
(\mathrm{mm} / \mathrm{h})\end{array}$ & $0.0-20$ & 93 & - & 110 & - \\
\hline $\begin{array}{l}\text { Haptoglobın } \\
\text { (mg/dL) }\end{array}$ & $38.0-195$ & 276 & - & - & - \\
\hline
\end{tabular}

Smear

description

Leukocytosis with neutrophilia, lymphocytosis with many reactive appearing or variant lymphocytes, plasma cells, and marked eosinophilia. Anemia with mild microsytosis. Thrombocytopenia, mild. No blasts. No overtly malignant cells or evidence of hemolytic process. 


\section{Cureus}

\begin{tabular}{|c|c|c|c|c|c|}
\hline \multicolumn{3}{|c|}{ Chemistry } & & & \\
\hline Sodium (mEq/L) & $136-145$ & 130 & 137 & 137 & 137 \\
\hline $\begin{array}{l}\text { Potassium } \\
(\mathrm{mEq} / \mathrm{L})\end{array}$ & $3.5-5.1$ & 3.9 & 3.4 & 4.1 & 3.9 \\
\hline Chloride (mEq/L) & $97-109$ & 97 & 107 & 109 & 103 \\
\hline $\begin{array}{l}\text { Carbon dioxide } \\
(\mathrm{mEq} / \mathrm{L})\end{array}$ & $23-32$ & 23 & 28 & 24 & 25 \\
\hline $\begin{array}{l}\text { Blood urea } \\
\text { nitrogen (mg/dL) }\end{array}$ & $6-17$ & 23 & 14 & 9 & 9 \\
\hline $\begin{array}{l}\text { Creatinine } \\
(\mathrm{mg} / \mathrm{dL})\end{array}$ & $0.7-1.1$ & 1.25 & 0.8 & 0.73 & 0.9 \\
\hline Glucose (mg/dL) & $66-111$ & 104 & 154 & 143 & 148 \\
\hline Calcium (mg/dL) & $8.7-10.1$ & 9.1 & 8.3 & 8.6 & 9.3 \\
\hline $\begin{array}{l}\text { Phosphorus } \\
\text { (mg/dL) }\end{array}$ & $2.5-4.5$ & 1.7 & 2.7 & 4.3 & - \\
\hline $\begin{array}{l}\text { Magnesium } \\
(\mathrm{mg} / \mathrm{dL})\end{array}$ & $1.6-2.6$ & 2.3 & 1.7 & 1.6 & - \\
\hline Uric acid (mg/dL) & $2.6-6.0$ & 9.8 & 5.8 & 2.9 & - \\
\hline $\begin{array}{l}\text { Total bilirubin } \\
(\mathrm{mg} / \mathrm{dL})\end{array}$ & $0.3-1.2$ & 0.7 & - & 0.4 & 0.7 \\
\hline $\begin{array}{l}\text { Aspartate } \\
\text { aminotransferase } \\
\text { (units/L) }\end{array}$ & $8-41$ & 22 & - & 20 & 21 \\
\hline $\begin{array}{l}\text { Alanine } \\
\text { aminotransferase } \\
\text { (units/L) }\end{array}$ & $12-48$ & 23 & - & 19 & 22 \\
\hline $\begin{array}{l}\text { Alkaline } \\
\text { phosphatase } \\
\text { (units/L) }\end{array}$ & $55-145$ & 85 & - & 89 & 83 \\
\hline $\begin{array}{l}\text { Lactate } \\
\text { dehydrogenase } \\
\text { (units/L) }\end{array}$ & $112-236$ & 385 & - & - & 186 \\
\hline $\begin{array}{l}\text { C-reactive } \\
\text { protein (mg/L) }\end{array}$ & $0.2-8.0$ & 90 & - & 4.5 & - \\
\hline $\begin{array}{l}\text { Total protein } \\
(\mathrm{g} / \mathrm{dL})\end{array}$ & $6.1-7.7$ & 9 & 8.4 & 0 & 9.9 \\
\hline Albumin (g/dL) & $3.8-5.1$ & 3.5 & 2.8 & 2.8 & 3.4 \\
\hline Ferritin (ng/dL) & $10-322$ & - & 254.2 & - & - \\
\hline
\end{tabular}




\section{Cureus}

Thyroid

stimulating

hormone $(\mathrm{mIU} / \mathrm{L})$

\section{TABLE 1: Laboratory data.}

Blood smear demonstrated reactive lymphocytes without circulating blasts. Flow cytometry did not show any abnormal lymphoid populations. Extensive infectious work up was negative, with the exception of Epstein-Barr virus (EBV) polymerase chain reaction (PCR) (Table 2).

\begin{tabular}{|c|c|c|}
\hline Test & Reference range & Day 0 \\
\hline Epstein-Barr virus PCR (IU/mL) & Not detected & 33,600 \\
\hline Rapid plasma reagin & Nonreactive & Nonreactive \\
\hline Cytomegalovirus DNA PCR & Not detected & Not detected \\
\hline Human immunodeficiency virus $1 \& 2$ antibody & Nonreactive & Nonreactive \\
\hline Herpes simplex virus $1 \& 2$ PCR & Not detected & Not detected \\
\hline QuantiFERON@-TB Gold & Negative & Negative \\
\hline Toxoplasma gondii DNA PCR & Not detected & Not detected \\
\hline Hepatitis A IgM & Nonreactive & Nonreactive \\
\hline Hepatitis B panel ${ }^{\star \star}$ & Nonreactive & Nonreactive \\
\hline Hepatitis C antibody & Nonreactive & Nonreactive \\
\hline
\end{tabular}

TABLE 2: Serology.

A computed tomography (CT) scan (Figure 1) revealed marked lymphadenopathy and hepatosplenomegaly. Positron emission tomography (PET) imaging (Figure 2) showed widespread hypermetabolic bulky lymphadenopathy and diffuse bone, spleen, and marrow uptake without osseous lesions. 


\section{Cureus}

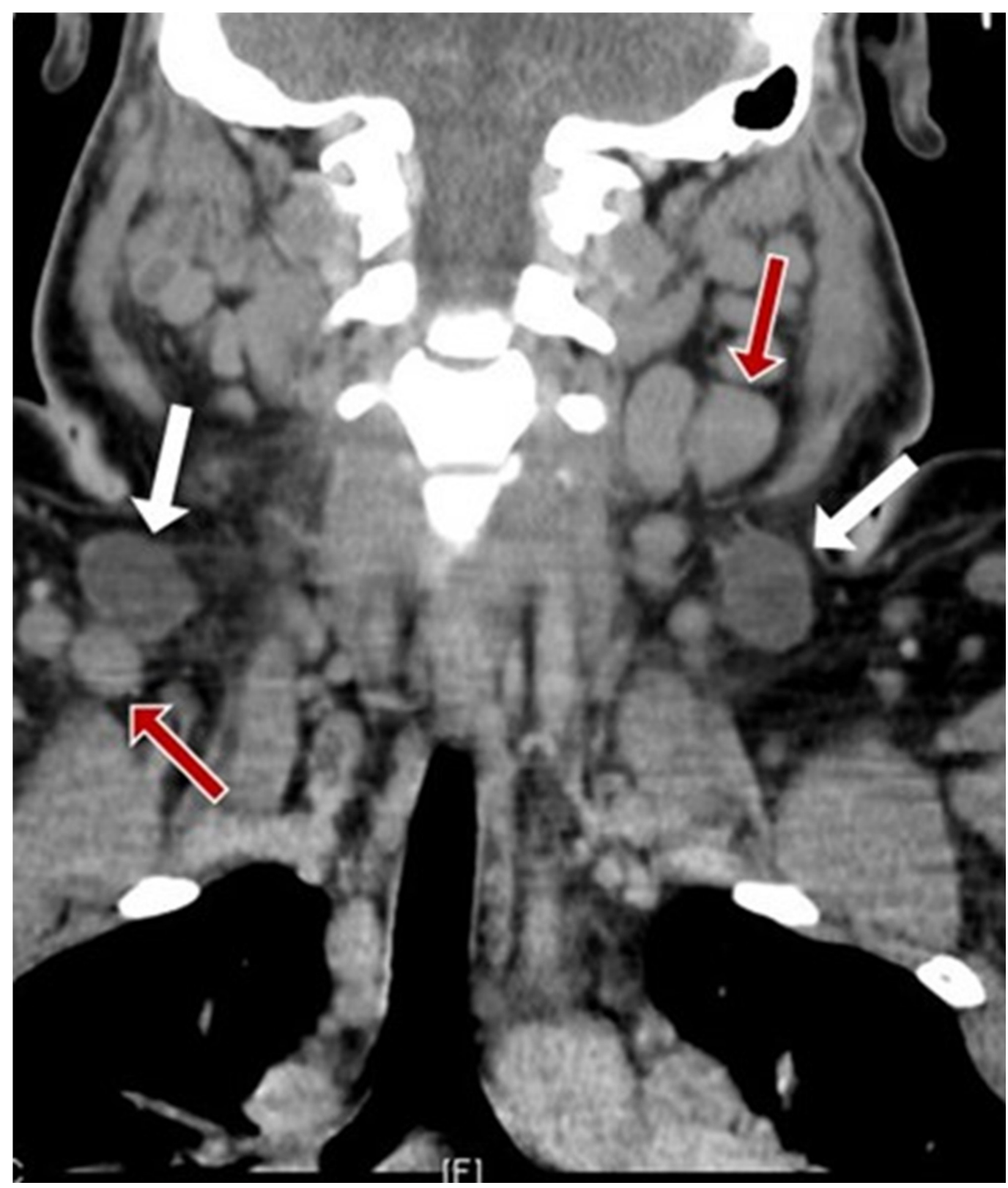

FIGURE 1: Computed tomography (CT) of the neck and chest.

Marked cervical, supraclavicular, mediastinal, and upper abdominal lymphadenopathy and hepatosplenomegaly. Centrally necrotic cervical lymph nodes (white arrows) are compared to enlarged, but non-necrotic, lymph nodes (red arrows). 


\section{Cureus}

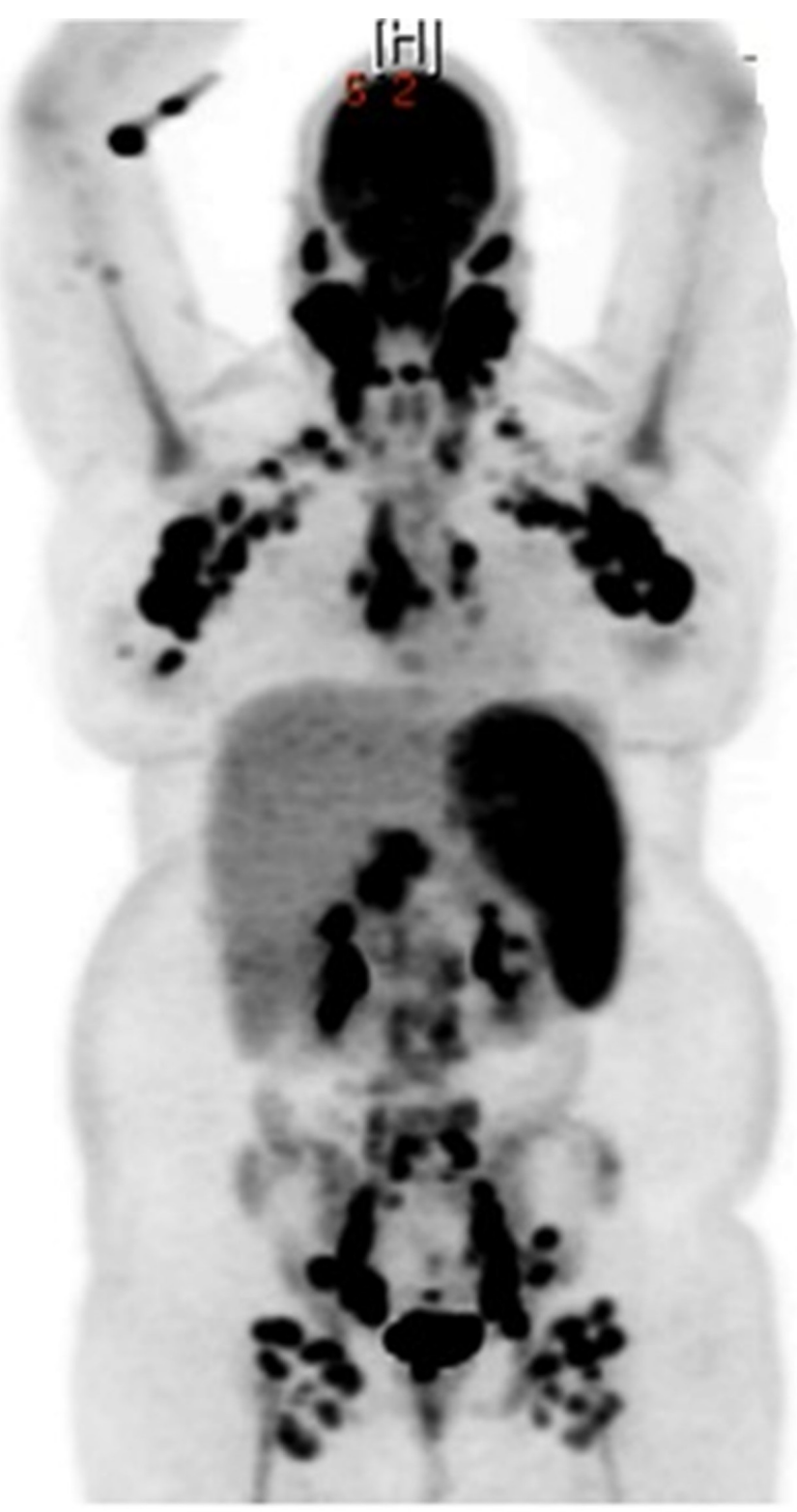

\section{FIGURE 2: Positron emission tomography (PET) scan.}

Widespread hypermetabolic bulky lymphadenopathy. Standardized uptake values (SUVs) ranged from 9.9 to 15.0. Mild diffuse bone marrow uptake was present, but no hypermetabolic osseous lesions were identified. Spleen appeared to be involved with SUV up to 7.0.

Excisional lymph node biopsy of a submental node revealed necrotizing lymphadenitis characterized by immunoblasts, myeloperoxidase-positive histiocytes with crescent shaped nuclei, and extensive necrosis with karyorrhectic debris (Figure 3). 


\section{Cureus}
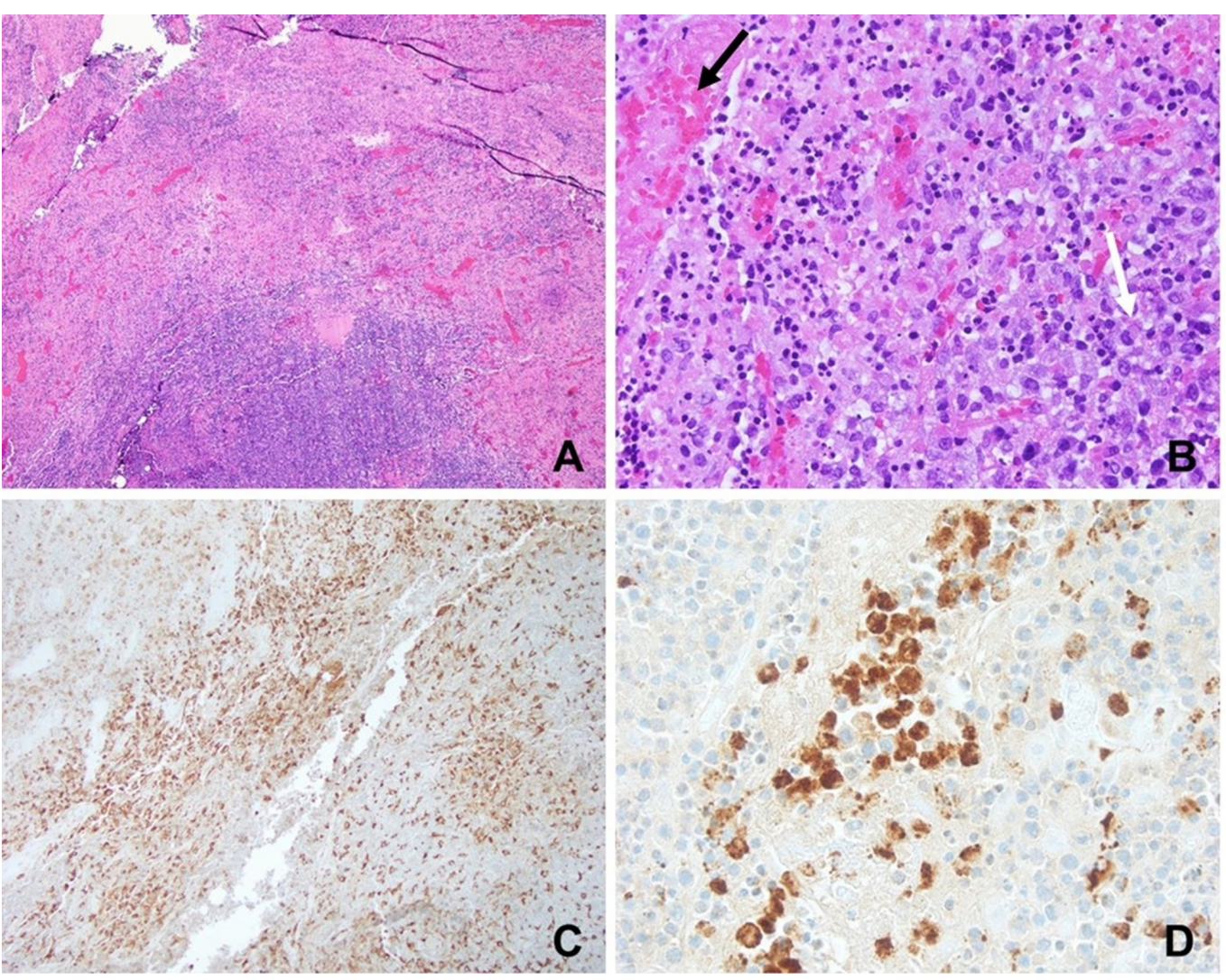

\section{FIGURE 3: Excisional lymph node biopsy.}

(A) Extensive necrosis (pink), 40x. (B) Necrosis with karyorrhectic debris (black arrow) adjacent to sheets of histiocytes (white arrows). (C) CD68 immunohistochemical stain highlighting increased histiocytes in brown. (D) Myeloperoxidase-positive histiocytes (brown).

There was no eosinophilic or neutrophilic infiltrate, or evidence of malignancy on biopsy or flow cytometry. Stains for acid-fast bacteria, fungi, herpes simplex virus, and cytomegalovirus were negative. Autoimmune workup was unrevealing (Table 3). 


\section{Cureus}

\begin{tabular}{|c|c|c|c|}
\hline Variable & Reference range & Presentation & Day 23 (Outpatient) \\
\hline Rheumatoid factor screen (u/mL) & $<10$ & $<10$ & - \\
\hline Cyclic citrullinated peptide Ab (CCP) & Negative & Negative & - \\
\hline \multirow{2}{*}{ Anti-nuclear antibody (ANA) } & \multirow{2}{*}{ Negative } & Negative & Positive \\
\hline & & $<1: 40$ & $1: 120$ \\
\hline Reichlin panel** & Negative & Negative & - \\
\hline Anti-neutrophil cytoplasmic antibody & $<1: 20$ & $1: 40$ & $<1: 20$ \\
\hline Complement C3 & 83.0-157 & 123 & 160 \\
\hline Complement C4 & 13-35 & 2.4 & 26 \\
\hline
\end{tabular}

\section{TABLE 3: Immunological studies.}

The patient's hospital course was uneventful. She received three doses of ceftriaxone for urinalysis findings consistent with urinary tract infection and was treated symptomatically with analgesics and anti-histamines. The patient's fever, rash, and lab abnormalities resolved spontaneously by day 5 of hospitalization and her lymphadenopathy decreased dramatically by discharge.

\section{Discussion}

Our case highlights a unique presentation of KFD in the setting of EBV infection. Diffuse lymphadenopathy, while rare, has been reported. To our knowledge, KFD has not been associated with the degree of leukocytosis or plasma cells on biopsy seen in our patient. These findings coupled with high titer EBV PCR and negative ANA suggest that EBV influenced the development of KFD in our patient.

\section{Presentation}

Although excisional lymph node biopsy is imperative for KFD diagnosis, clinical presentation and course support the diagnosis. KFD occurs most frequently in Asian populations, but has a worldwide distribution. KFD typically presents prior to the fourth decade, but there have been cases in pediatric and elderly populations. Female to male ratio ranges from $1: 1$ to $4: 1$, depending on the cohort [6, 8-11].

Kikuchi-Fujimoto disease presents acutely or sub-acutely. Common findings include cervical lymphadenopathy, fever, headache, weight loss, fatigue and nonspecific viral-like symptoms. Nonspecific skin manifestation (rashes, nodules, and erythema multiforme), hepatosplenomegaly, and diffuse lymphadenopathy may be present and likely indicate more severe disease $[3,6,8,10]$. In a review of 91 cases consisting of predominately non-Asian females with KFD, Dumas found that $52 \%$ of patients exhibited generalized lymphadenopathy which is a significantly higher proportion compared to previous Asian predominant cohorts 


\section{Cureus}

suggesting that KFD may present differently in non-Asian populations [2-3, 10].

Common laboratory findings include elevated inflammatory markers, leukopenia/lymphopenia, anemia, atypical lymphocytes, thrombocytopenia, and increased lactate dehydrogenase and alanine aminotransferase. Leukocytosis has been reported in $2 \%-5 \%$ of cases $[6,9-10,12]$. To our knowledge, the degree of leukocytosis, especially the eosinophilia demonstrated by our patient, has not been reported (Table 4).

\section{Diagnosis}

\section{Characteristic findings in Kikuchi-Fujimoto disease}

Focal lesions situated in the lymph node cortex or paracortex

Severe coagulative necrosis with karyorrhexis

Absence of large numbers of large numbers of neutrophils and eosinophils (plasma cells are also typically scarce)

Histiocytes at the margin of necrotic areas (possibly foamy or crescent shaped)

Variable plasmacytoid monocytes, lymphocytes, and immunoblast

\section{TABLE 4: Characteristic findings in Kikuchi-Fujimoto disease based on lymph node biopsy.}

Reaching a diagnosis of KFD promptly is important to limit unnecessary interventions. KFD must be distinguished from other causes of lymphadenopathy and fever such as malignancy, autoimmunity (sarcoidosis, SLE, lupus lymphadenitis), and infection (EBV, HIV, tuberculosis, Bartonella, toxoplasmosis). Histological examination of an excised lymph node is the cornerstone of KFD diagnosis.

Tsang and colleagues concluded that the minimal diagnostic criteria for KFD include the presence of foci, histiocytes, and plasmacytoid monocytes with a paucity of neutrophils, overt infection, or malignancy [6, 8-9]. Lymphoid follicles or follicular hyperplasia can also been seen. Immunohistochemical stains demonstrate CD68+/myeloperoxidase (MPO)+ histiocytes, CD68+/CD123 plasmacytoid dendritic cells, variable CD8+ lymphocytes and immunoblasts [6$10]$.

\section{Etiology and associations}

The etiology of KFD remains controversial. Features of KFD suggest autoimmune or viral etiology. KFD shares many clinical and histopathologic features of a viral infection [6]. Although EBV, human herpesvirus 6, human herpesvirus 8, parvovirus B-19, herpes simplex, cytomegalovirus, and varicella zoster have all been suggested to play a role in KFD pathogenesis, no study has demonstrated clear causality [4, 10, 13-14]. EBV has been examined extensively. Some of the most convincing cases suggesting EBV induced KFD have been in children. Yen et al. describes a 6-year-old boy with diffuse lymphadenopathy, biopsy consistent with KFD, and evidence of active EBV infection based on PCR and immunoperoxidase staining. Others have found no significant difference in the number EBV infected cells in lymphoid tissues of those with KFD compared to controls [14-17]. Some postulate that the absence of EBV infected cells within the lymph nodes does not negate EBV involvement in KFD but rather 
supports a cytotoxic immune response to EBV infected cells resulting in KFD [15].

Lymph node histology in EBV lymphadenitis differs from that of KFD. Numerous polyclonal plasma cells, absent eosinophils, and CD30+ immunoblasts (seen in our patient) can be seen in EBV lymphadenitis. However, EBV lymphadenitis is associated with significant follicular hyperplasia, Reed Sternberg cells, and an inverted CD4:CD8 ratio [18-20]. In addition, prominent histiocytes and widespread karyorrhexis are not typical of EBV infection.

There are reports of SLE being diagnosed before, simultaneously, or after and KFD diagnosis [3, $5,8,10-11]$. Interestingly, our patient had a negative ANA that turned positive. It is important to realize that a positive ANA can be seen in the general population and transient elevations are common following viral infections. Lupus lymphadenitis can be difficult to distinguish from KFD. However, the distinctive histiocytes and plasmacytoid monocytes of KFD are lacking in SLE. Plasma cells, hematoxylin bodies, and neutrophils are usually apparent in SLE, but minimal in KFD [7-8]. Our patient was atypical in that she had a significant number of plasma cells on biopsy. The absence of neutrophils, hematoxylin bodies, negative ANA, and selfresolving course make SLE an unlikely diagnosis. However, the association underscores the need for follow up in those diagnosed with KFD.

Given the rarity of KFD, identifying a clear cause is difficult. KFD is likely a transient autoimmune reaction triggered by a nonspecific viral infection in a genetically susceptible host. In our patient, high EBV viral load plus the typical pathological features of KFD suggests widespread necrotizing lymphadenitis triggered by EBV.

\section{Disease course}

Kikuchi-Fujimoto disease is generally a benign self-limited disease with a recurrence rate of $<5 \%[3,6,8-10,12]$. It is in this authors' opinion that the benign nature of KFD is essential for diagnosis.

\section{Conclusions}

Kikuchi-Fujimoto disease is a difficult-to-diagnose disease characterized by fever, lymphadenopathy, specific biopsy findings, and benign course. Prompt diagnosis with excisional lymph node biopsy is imperative to diagnose and manage patients appropriately. Therapy is rarely indicated in KFD, and when required is geared towards symptomatic management. Our patient's biopsy findings and complete resolution of symptoms without intervention supported a diagnosis of KFD in the setting of EBV infection.

\section{Additional Information \\ Disclosures}

Human subjects: Consent was obtained by all participants in this study. Conflicts of interest: In compliance with the ICMJE uniform disclosure form, all authors declare the following: Payment/services info: All authors have declared that no financial support was received from any organization for the submitted work. Financial relationships: All authors have declared that they have no financial relationships at present or within the previous three years with any organizations that might have an interest in the submitted work. Other relationships: All authors have declared that there are no other relationships or activities that could appear to have influenced the submitted work.

\section{References}

1. Fujimoto Y, Kojima Y, Yamaguchi K: Cervical subacute necrotizing lymphadenitis . New 
Clinicopathol Ent. 1972, 20:920-927.

2. Kikuchi M: Lymphadenitis showsing focal reticulum cell hyperplasia with nuclear debris and phagocytosis. Nippon Ketsueki Gakkai Zasshi. 1972, 35:379-380.

3. Dumas G, Prendki V, Haroche J, et al.: Kikuchi-Fujimoto disease: retrospective study of 91 cases and review of the literature. Medicine (Baltimore). 2014, 93:372-382.

10.1097/MD.0000000000000220

4. Rosado FG, Tang YW, Hasserjian RP, McClain CM, Wang B, Mosse CA: Kikuchi-Fujimoto lymphadenitis: role of parvovirus B-19, Epstein-Barr virus, human herpesvirus 6, and human herpesvirus 8. Hum Pathol. 2013, 44:255-259. 10.1016/j.humpath.2012.05.016

5. Sopena B, Rivera A, Vazquez-Trinanes C, et al.: Autoimmune manifestations of Kikuchi disease. Semin Arthritis Rheum. 2012, 41:900-906. 10.1016/j.semarthrit.2011.11.001

6. Bosch X, Guilabert A, Miquel R, Campo E: Enigmatic Kikuchi-Fujimoto disease: a comprehensive review. Am J Clin Pathol. 2004, 122:141-152. 10.1309/YF08-1L4T-KYWVYVPQ

7. Pepe F, Disma S, Teodora C, Pepe P, Magro G: Kikuchi-Fujimoto disease: a clinicopathologic update. Pathologica. 2015, 107:120-129.

8. Tsang W, Chan J, Ng CS: Kikuchi's lymphadenitis: a morphologic analysis of 75 cases with special reference to unusual features. Am J Surg Pathol. 1994, 18:219-231.

9. Kuo TT: Kikuchi's disease (histiocytic necrotizing lymphadenitis). A clinicopathologic study of 79 cases with an analysis of histologic subtypes, immunohistology, and DNA ploidy. Am J Surg Pathol. 1995, 19:798-809.

10. Kucukardali Y, Solmazgul E, Kunter E, Oncul O, Yildirim S, Kaplan M: Kikuchi-Fujimoto disease: analysis of 244 cases. Clin Rheumatol. 2007, 26:50-54. 10.1007/s10067-006-0230-5

11. Mahmood A, Mir R, Salama SR, Miarrostami RM, Lapidus C, Pujol F: Kikuchi's disease: an unusual presentation and a therapeutic challenge. Yale J Biol Med. 2006, 79:27-33.

12. Lin HC, Su CY, Huang CC, Hwang CF, Chien CY: Kikuchi's disease: a review and analysis of 61 cases. Otolaryngol Head Neck Surg. 2003, 128:650-653.

13. Chong Y, Kang CS: Causative agents of Kikuchi-Fujimoto disease (histiocytic necrotizing lymphadenitis): a meta-analysis. Int J Pediatr Otorhinolaryngol. 2014, 78:1890-1897. 10.1016/j.ijporl.2014.08.019

14. Maeda N, Yamashita Y, Kimura H, Hara S, Mori N: Quantitative analysis of herpesvirus load in the lymph nodes of patients with histiocytic necrotizing lymphadenitis using a real-time PCR assay. Diagn Mol Pathol. 2006, 15:49-55.

15. Anagnostopoulos I, Hummel M, Korbjuhn P, Papadaki T, Anagnostou D, Stein H: Epstein-Barr virus in Kikuchi-Fujimoto disease. Lancet. 1993, 341:893.

16. Yen A, Fearneyhough P, Raimer SS, Hudnall SD: EBV-associated Kikuchi's histiocytic necrotizing lymphadenitis with cutaneous manifestations. J Am Acad Dermatol. 1997, 36:342346.

17. Martinez-Vazquez C, Potel C, Angulo M, et al.: Nosocomial Kikuchi's disease--a search for herpesvirus sequences in lymph node tissues using PCR. Infection. 2001, 29:143-147.

18. Thomas DL, Syrbu S, Graham MM: Epstein-Barr virus mimicking lymphoma on FDG-PET/CT . Clin Nucl Med. 2009, 34:891-893. 10.1097/RLU.0b013e3181bed135

19. Louissaint A, Jr., Ferry JA, Soupir CP, Hasserjian RP, Harris NL, Zukerberg LR: Infectious mononucleosis mimicking lymphoma: distinguishing morphological and immunophenotypic features. Mod Pathol. 2012, 25:1149-1159. 10.1038/modpathol.2012.70

20. Cattoir L, Van Hende V, De Paepe P, Padalko E: Epstein-Barr virus serology and PCR: conflicting results in an immunocompetent host. A case report and review of literature. Acta Clin Belg. 2014, 69:262-266. 10.1179/2295333714Y.0000000037 